\title{
Urea cycle disorders: a life-threatening yet treatable cause of metabolic encephalopathy in adults
}

\author{
Nicholas F Blair, ${ }^{1}$ Philip D Cremer, ${ }^{1}$ Michel C Tchan $^{2}$
}

\begin{abstract}
${ }^{1}$ Department of Neurology, Royal North Shore Hospital, Sydney, Australia

${ }^{2}$ Adult Genetic Metabolic Disorders Service, Westmead Hospital, Sydney, Australia
\end{abstract}

\section{Correspondence to}

Dr Michel C Tchan, Department of Genetic Medicine, Westmead Hospital, Hawkesbury Road, Westmead NSW 2145, Australia; michel.tchan@health.nsw.gov.au

Accepted 24 June 2014 Published Online First 14 August 2014

\section{CrossMark}

\footnotetext{
To cite: Blair NF, Cremer PD, Tchan MC. Pract Neurol 2015;15:45-48.
}

\begin{abstract}
Urea cycle disorders are inborn errors of metabolism that, in rare cases, can present for the first time in adulthood. We report a perplexing presentation in a woman 4 days postpartum of bizarre and out-of-character behaviour interspersed with periods of complete normality. Without any focal neurological signs or abnormality on initial investigations, the diagnosis became clear with the finding of a significantly elevated plasma ammonia level, just as she began to deteriorate rapidly. She improved following intravenous dextrose and lipid emulsion, together with sodium benzoate, arginine and a protein-restricted diet. She remains well 12 months later with no permanent sequelae. Whilst this is a rare presentation of an uncommon disease, it is a treatable disorder and its early diagnosis can prevent a fatal outcome.
\end{abstract}

\section{CASE REPORT}

A 38-year-old woman presented 5 days postpartum with an acute onset behavioural disturbance. She had been primigravid with an uncomplicated antenatal period other than breech presentation, requiring delivery by caesarean section. She had vomited twice the day before, but was otherwise well. During the night her husband woke to find her confused. She asked how he had entered the house and repeatedly told him to get out. She appeared to mistake her husband for his brother, and could not recall her recent childbirth. She became uncharacteristically aggressive and violent, and an ambulance was called.

On arrival in hospital, she was disorientated, markedly agitated and unable to follow commands. There was no meningism or focal neurological signs. She was afebrile and the remainder of examination was normal. There was no significant past medical history. She was taking no regular medications other than analgesics for postoperative pain. She had no previous mood disorder or other psychiatric condition. There was no recent alcohol intake or history of substance abuse.

Her initial blood results showed multiple mild abnormalities (table 1), many of which could be explained by recent pregnancy; in particular, there was no renal or hepatic dysfunction, other than mildly elevated serum alkaline phosphatase, which may have been due to placental production. Her CT scan of head was normal. CSF protein was mildly elevated at $0.58 \mathrm{~g} / \mathrm{L}(0.15-0.45)$ with normal CSF glucose and cell counts; Gram stain was negative.

By the next morning, her clinical status had completely normalised. Detailed neurological and psychiatric assessments were normal. In the absence of any alternative explanation, a provisional diagnosis of post-partum psychosis was made, although further investigations were awaited. Later that evening, her behavioural state relapsed. She became disorientated with fluctuating responses to cognitive tasks and profound amnesia for recent events. She had marked verbal and motor perseveration. On asking her to stand from a chair, for example, she performed this task repetitively until stopped. The remaining examination was normal, apart from subtle asterixis.

Her MR scan of brain was normal. Her EEG showed generalised delta slowing but no specific abnormality. Her plasma ammonia was significantly elevated at $292 \mu \mathrm{mol} / \mathrm{L}$ (normal 10-50). Shortly thereafter, she markedly deteriorated, requiring admission to the intensive care unit, with progressively declining responsiveness and prominent asterixis.

Arterial blood gas results demonstrated a respiratory alkalosis with $\mathrm{pH} 7.52$ (RR 7.35-7.45), pCO2 $29 \mathrm{mmHg}$ (RR 32-45 
Table 1 Initial blood test results

\begin{tabular}{|c|c|c|c|c|}
\hline Test & Resu & & $\begin{array}{l}\text { Normal } \\
\text { range }\end{array}$ & $\begin{array}{l}\text { Range in } \\
\text { pregnancy }\end{array}$ \\
\hline Haemoglobin ( $\mathrm{g} / \mathrm{L}$ ) & 108 & $\downarrow$ & $115-160$ & $110-150$ \\
\hline White cell count $\left(\times 10^{9} / \mathrm{L}\right)$ & 5.0 & & $4.0-11.0$ & \\
\hline Platelet count $\left(\times 10^{9} / \mathrm{L}\right)$ & 312 & & $150-400$ & \\
\hline Serum sodium (mmol/L) & 146 & $\uparrow$ & $134-145$ & $132-140$ \\
\hline Serum potassium (mmol/L) & 3.3 & $\downarrow$ & $3.5-5.0$ & $3.2-4.6$ \\
\hline Serum chloride (mmol/L) & 108 & $\uparrow$ & $97-107$ & $97-109$ \\
\hline Serum bicarbonate (mmol/L) & 20 & $\downarrow$ & $24-34$ & $18-26$ \\
\hline Serum urea $(\mathrm{mmol} / \mathrm{L})$ & 2.7 & $\downarrow$ & $3.1-8.1$ & $1.0-3.8$ \\
\hline Serum creatinine $(\mu \mathrm{mol} / \mathrm{L})$ & 40 & $\downarrow$ & 49-90 & $40-80$ \\
\hline Anion gap (mmol/L) & 22 & $\uparrow$ & $7-17$ & $11-18$ \\
\hline Serum albumin (g/L) & 32 & $\downarrow$ & $35-46$ & $24-31$ \\
\hline Serum bilirubin ( $\mu \mathrm{mol} / \mathrm{L})$ & 3 & & $3-18$ & \\
\hline $\begin{array}{l}\text { Serum alkaline phosphatase } \\
\text { (U/L) }\end{array}$ & 161 & $\uparrow$ & $41-119$ & $125-250$ \\
\hline $\begin{array}{l}\text { Serum } \gamma \text { glutamyl } \\
\text { transferase (U/L) }\end{array}$ & 9 & & $5-65$ & \\
\hline $\begin{array}{l}\text { Serum alanine } \\
\text { aminotransferase (U/L) }\end{array}$ & 40 & & $5-40$ & \\
\hline $\begin{array}{l}\text { Serum aspartate } \\
\text { aminotransferase (U/L) }\end{array}$ & 36 & & $12-36$ & \\
\hline
\end{tabular}

References ranges for pregnancy are given for results that were outside of the routine reference ranges.

$\mathrm{mmHg}$ ) and $\mathrm{HCO}_{3} 24 \mathrm{mmol} / \mathrm{L}(24-32 \mathrm{mmHg})$. Her repeat ammonium level was $382 \mu \mathrm{mol} / \mathrm{L}$. A urea cycle disorder was considered likely and treatment was started before confirmatory results were available. She was given 10\% dextrose and 20\% lipid emulsion (Intralipid) infusions intravenously. Treatment with sodium benzoate and arginine was also commenced and her diet was restricted to $<5 \mathrm{~g} /$ day of protein.

She improved over the next $24 \mathrm{~h}$ and, by $48 \mathrm{~h}$, was alert and orientated with a serum ammonia concentration of $50 \mu \mathrm{mol} / \mathrm{L}$. We continued treatment with intravenous calories, benzoate and arginine for 3 days, before changing to oral arginine. Her plasma amino acids (taken prior to treatment) revealed a low arginine and citrulline, and her urine testing showed elevated orotate, consistent with a diagnosis of ornithine transcarbamylase (OTC) deficiency. Following discharge, she needed additional oral benzoate to maintain stable ammonia levels. She remains well 12 months later.

Sequencing of all exons, including intron/exon boundaries, of the OTC gene showed no pathogenic mutation. This occurs in approximately $30 \%$ of biochemically confirmed OTC deficiency cases and is likely due to intronic or promoter mutations. The patient has one sister who was well and there was no family history of unexpected male deaths. A protein loading challenge ${ }^{1}$ showed that her sister was unaffected.

\section{DISCUSSION}

Urea cycle disorders are inborn errors of metabolism where there is a genetic defect in one of the enzymes

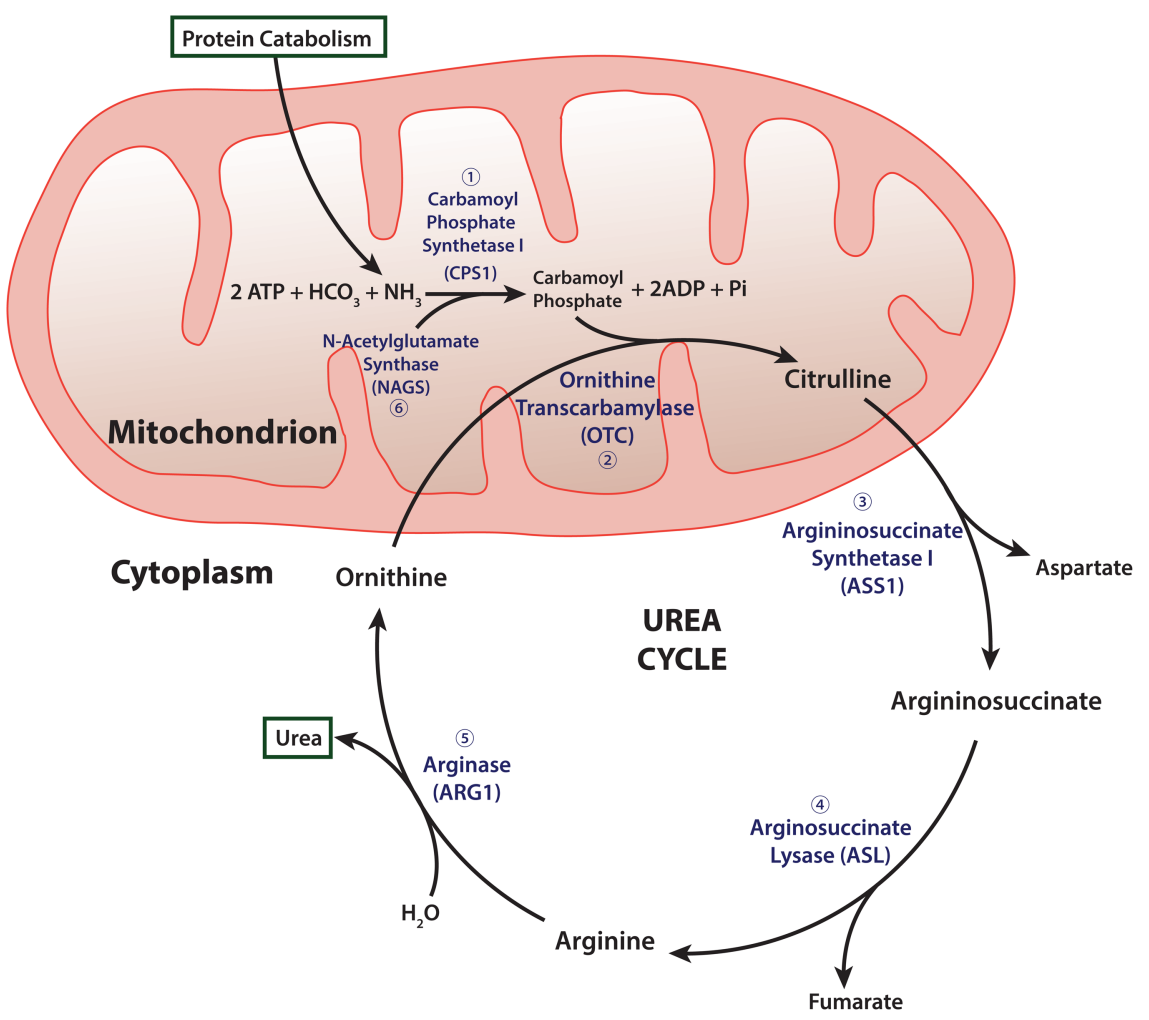

Figure 1 The urea cycle produces urea from the nitrogenous waste products of protein metabolism. The six enzymes of the pathway are numbered 1-6, with their associated gene in brackets. 
NEUROLOGICAL RARITIES

Table 2 Urea cycle disorders and expected investigation results

\begin{tabular}{|c|c|c|c|c|}
\hline Urea cycle disorder & Gene & Inheritance & Plasma amino acids & Urine organic acids \\
\hline Carbamoylphosphate synthetase I deficiency & CPS1 & Autosomal recessive & $\begin{array}{l}\downarrow \text { Arginine } \\
\downarrow \text { Citrulline }\end{array}$ & $\downarrow /$ Normal urinary orotic acid \\
\hline Ornithine transcarbamylase deficiency & OTC & $X$ linked & $\begin{array}{l}\downarrow \text { Arginine } \\
\downarrow \text { Citrulline }\end{array}$ & $\uparrow$ Urinary orotic acid \\
\hline $\begin{array}{l}\text { Argininosuccinic acid synthase deficiency or } \\
\text { citrullineamia type I }\end{array}$ & ASS1 & Autosomal recessive & $\begin{array}{l}\uparrow \text { Arginine } \\
\uparrow \text { Citrulline }\end{array}$ & \\
\hline $\begin{array}{l}\text { Argininosuccinase acid lyase deficiency or } \\
\text { argininosucciniaciduria }\end{array}$ & ASL & Autosomal recessive & $\begin{array}{l}\uparrow \text { Arginine } \\
\uparrow \text { Citrulline }\end{array}$ & \\
\hline Arginase deficiency & ARG1 & Autosomal recessive & $\uparrow \uparrow$ Arginine & \\
\hline $\mathrm{N}$-acetylglutamate synthase deficiency & NAGS & Autosomal recessive & $\begin{array}{l}\downarrow \text { Arginine } \\
\downarrow \text { Citrulline }\end{array}$ & $\downarrow$ /Normal urinary orotic acid \\
\hline
\end{tabular}

Plasma amino acid and urinary organic acid levels indicated as being low $(\downarrow)$ or high $(\uparrow)$ relative to the reference range.

of the urea cycle, which is responsible for the metabolism of nitrogen waste from the breakdown of proteins (figure 1). In doing so, the cycle produces urea from ammonia. The urea cycle is also the only endogenous source of the amino acids arginine, ornithine and citrulline. In humans, this biochemical pathway occurs primarily in the liver, but to a lesser extent in the kidney. The incidence of urea cycle disorders is about 1:35000 live births. ${ }^{2}$

Classically, urea cycle disorders present in the neonatal period with vomiting, anorexia and lethargy that rapidly progresses to encephalopathy, coma and death if untreated. Plasma ammonia of greater than 1000 $\mu \mathrm{mol} / \mathrm{L}$ may be found in these circumstances and results from a severe deficiency or total absence of any of the first four enzymes in the urea cycle (CPS1, OTC, ASS, ASL) or the cofactor NAGS. In cases where there is only a partial deficiency of these enzymes, or in arginase deficiency, the symptoms may be mild or not develop until adulthood. As recognition of these disorders has improved, it has emerged than only a third of patients present in the neonatal period, with the majority in childhood, but less than $10 \%$ over the age of $16 .^{3}$

In adults, symptoms of this disorder may include intellectual impairment, nausea, vomiting, headaches, ataxia, protein intolerance, psychiatric disease and encephalopathy. In rare cases, other focal neurological signs may occur. Respiratory alkalosis is a common early finding caused by hyperventilation secondary to the effect of hyperammonaemia on the brainstem. However, the first sign may be an acute life-threatening encephalopathy. We are aware of a similar case at another hospital, where the diagnosis of a urea cycle disorder was not recognised, with a fatal outcome. Indeed, in several reported adult cases the initial presentation was fatal. ${ }^{4-6}$

In adult cases presenting in acute metabolic crisis, there is often an identifiable precipitant such as an increased protein load, or physiological stress such as an intercurrent illness or surgery. Medications including valproate, salicylates, corticosteroids and
L-asparaginase may also precipitate a hyperammonaemic crisis. As in this case, women with OTC deficiency are at risk of decompensation during the post-partum period, ${ }^{7}$ due to the increased catabolic protein load following involution of the uterus.

In an adult presenting with acute encephalopathy, there may be no other suggestion in the clinical assessment that the condition might be related to a genetic metabolic disorder, highlighting the importance of plasma ammonia testing, even when there is no evidence of hepatic or renal dysfunction. In adults, a plasma ammonia $>80 \mu \mathrm{mol} / \mathrm{L}$, in the absence of renal or hepatic dysfunction, should raise suspicion of a urea cycle defect. Plasma amino acid and urine organic acid tests are used to distinguish the different urea cycle disorders (table 2).

OTC deficiency is the most common form of urea cycle disorder $(55 \%) .{ }^{3}$ Unlike other urea cycle disorders, which are recessive, its inheritance is $\mathrm{X}$ linked. Men classically have an infantile-onset, severe form. Female heterozygotes are not always asymptomatic with $15 \%$ developing symptoms. Women show considerable variation in clinical symptoms from minimally symptomatic illness to recurrent, severe hyperammonaemic coma and death. ${ }^{8}$

The principles of management of urea cycle disorders are to remove excess ammonia and prevent its production from protein metabolism. In the emergent setting, the fastest way to reduce ammonia levels is to use haemodialysis. Pharmacological strategies include the use of the nitrogen-scavenging agents, sodium phenylacetate and sodium benzoate, which provide alternative pathways for nitrogen disposal. Conjugation with ammonia occurs in the liver and is then excreted by the kidneys. The use of these drugs has been associated with a survival rate of $84 \%$ in a large observational study over 25 years, ${ }^{9}$ a dramatic improvement on the high infant mortality rates of historical cohorts.

Defects of some urea cycle enzymes also result in deficiency of amino acids that would be generated as a by-product. It may be necessary to replace arginine and/or citrulline, depending on which 
enzymes are affected. ${ }^{10}$ It is essential to avoid a catabolic state, particularly in the acute setting. This requires caloric supplementation with glucose, fats and amino acids. Dietary restriction of protein is an important aspect of management; however, this must be done judiciously to avoid induction of catabolism by an excessively low protein intake. Patients with severe forms of urea cycle disorders may ultimately require liver transplantation to prevent recurrent hyperammonaemic crises.

\section{Practice points}

Urea cycle disorders are a rare but important cause of acute encephalopathy and can present for the first time in adulthood.

- It is essential that adult neurologists be aware of this condition as it is readily treatable, but can be fatal if undiagnosed and untreated.

- Plasma ammonia level should be a routine investigation for metabolic encephalopathy.

- A plasma ammonia level $>80 \mu \mathrm{mol} / \mathrm{L}$ in a patient without renal or hepatic dysfunction should raise suspicion of the presence of a urea cycle defect.

- If a urea cycle disorder is suspected, diagnostic samples should be sent urgently and treatment, guided by a metabolic specialist, should be instituted prior to the diagnosis being confirmed. Crisis samples are critical for making the diagnosis and close liaison with laboratory personnel is important to ensure prioritisation and appropriate additional testing is undertaken.

Contributors NFB, PDC and MCT were involved in the clinical care of the patient. NFB wrote the first draft. The manuscript was critically reviewed and substantial revisions contributed by PDC and MCT.
Competing interests None.

Patient consent Obtained.

Provenance and peer review Not commissioned; externally peer reviewed. This paper was reviewed by Duncan Cole, Cardiff, UK.

\section{REFERENCES}

1 Potter M, Hammond JW, Sim KG, et al. Ornithine carbamoyltransferase deficiency: improved sensitivity of testing for protein tolerance in the diagnosis of heterozygotes. J Inherit Metab Dis 2001;24:5-14.

2 Summar ML, Koelker S, Freedenberg D, et al. The incidence of urea cycle disorders. Mol Genet Metab 2013;110:179-80.

3 Summar ML, Dobbelaere D, Brusilow S, et al. Diagnosis, symptoms, frequency and mortality of 260 patients with urea cycle disorders from a 21-year, multicentre study of acute hyperammonaemic episodes. Acta Paediatr 2008;97:1420-25.

4 Klein OD, Kostiner DR, Weisiger K, et al. Acute fatal presentation of ornithine transcarbamylase deficiency in a previously healthy male. Hepatol Int 2008;2:390-94.

5 Lien J, Nyhan WL, Barshop BA. Fatal initial adult-onset presentation of urea cycle defect. Arch Neurol 2007;64:1777-79.

6 Rohininath T, Costello DJ, Lynch T, et al. Fatal presentation of ornithine transcarbamylase deficiency in a 62-year-old man and family studies. J Inherit Metab Dis 2004;27:285-88.

7 Arn PH, Hauser ER, Thomas GH, et al. Hyperammonemia in women with a mutation at the ornithine carbamoyltransferase locus. A cause of postpartum coma. N Engl J Med 1990;322:1652-55.

8 Batshaw ML, Msall M, Beaudet AL, et al. Risk of serious illness in heterozygotes for ornithine transcarbamylase deficiency. J Pediatr 1986;108:236-41.

9 Enns GM, Berry SA, Berry GT, et al. Survival after treatment with phenylacetate and benzoate for urea-cycle disorders. N Engl J Med 2007;356:2282-92.

10 Lanpher BC, Gropman A, Chapman KA, et al. Urea cycle disorders overview. In: Pagon RA, Adam MP, Bird TD, et al. eds. GeneReviews. Seattle,WA: University of Washington, 2011. http://www.ncbi.nlm.nih.gov/books/NBK1217/ 